\title{
Electrochemical Fixation of Nitrogen and Its Coupling with Biomass Valorization with a Strongly Adsorbing and Defect Optimized Boron-Carbon-Nitrogen Catalyst
}

\author{
Q. Qin, ${ }^{* \dagger \odot}{ }^{\dagger}$ T. Heil, $^{\dagger}$ J. Schmidt, $^{\dagger}$ M. Schmallegger, ${ }^{\S}{ }^{\circledR}$ Georg Gescheidt, ${ }^{\S}$ M. Antonietti, ${ }^{\dagger}$ \\ and M. Oschatz ${ }^{*},, \|$
}

\author{
${ }^{\dagger}$ Department of Colloid Chemistry, Max Planck Institute of Colloids and Interfaces, Am Mühlenberg 1, 14476 Potsdam, Germany \\ ${ }^{\ddagger}$ Institute of Chemistry, Division of Functional Materials, Technische Universität Berlin, Hardenbergstraße 40, 10623 Berlin, \\ Germany \\ ${ }^{\S}$ Institute of Physical and Theoretical Chemistry, NAWI Graz, Graz University of Technology, Stremayrgasse 9, 8010 Graz, Austria \\ "Institute of Chemistry, University of Potsdam, Karl-Liebknecht-Str. 24-25, 14476 Potsdam, Germany
}

\section{Supporting Information}

\begin{abstract}
The electrochemical conversion of low-cost precursors into high-value chemicals using renewably generated electricity is a promising approach to build up an environmentally friendly energy cycle, including a storage element. The large-scale implementation of such process can, however, only be realized by the design of cost-effective electrocatalysts with high efficiency and highest stability. Here, we report the synthesis of $\mathrm{N}$ and $\mathrm{B}$ codoped porous carbons. The constructed $\mathrm{B}-\mathrm{N}$ motives combine abundant unpaired electrons and frustrated Lewis pairs (FLPs). They result in desirable performance for electrochemical $\mathrm{N}_{2}$ reduction reaction (NRR) and electrooxidation of 5-hydroxymethylfurfural (HMF) in the absence of any metal cocatalyst. A maximum Faradaic efficiency of $15.2 \%$ with a stable $\mathrm{NH}_{3}$ production rate of $21.3 \mu \mathrm{g} \mathrm{h}^{-1} \mathrm{mg}^{-1}$ is obtained in NRR. Besides, 2,5-furandicarboxylic acid (FDCA) is first obtained by using non-metalbased electrocatalysts at a conversion of $71 \%$ and with yield of $57 \%$. Gas adsorption experiments elucidate the relationship between the structure and the ability of the catalysts to activate the substrate molecules. This work opens up deep insights for the rational design of non-metal-based catalysts for potential electrocatalytic applications and the possible enhancement of their activity by the introduction of FLPs and point defects at grain boundaries.
\end{abstract}

KEYWORDS: non-metal catalysis, porous carbon, heteroatoms, $\mathrm{N}_{2}$ reduction, HMF oxidation

\section{INTRODUCTION}

Carbon-based materials are promising as metal-free electrocatalysts due to their low cost, high (electro)chemical stability, modifiable surface chemistry, and high electronic conductivity. ${ }^{1-7}$ Among various carbon modifications, porous carbon materials have attracted particular attention due to their large specific surface area and pore volumes. These properties are highly desired for heterogeneous electrocatalysts since a high specific surface area usually comes with a high density of catalytically active sites. ${ }^{8}$ Besides, the strength of interaction with substrate molecules and thus the catalytic performance of carbon materials can be tuned by doping of heteroatoms (e.g., $\mathrm{B}, \mathrm{N}, \mathrm{P}, \mathrm{S}, \mathrm{F}$, etc.). The incorporation of non-carbon atoms causes inhomogeneous charge distribution and modifies the work function of the electrons in the catalysts. These effects can be used to tailor the redox potential of the catalysts and to modify the electron transfer mechanism to the substrate molecules. $^{9-12}$ In consequence, many examples are known in which heteroatom-doped carbon materials show remarkable electrocatalytic performance, especially for the activation of small molecules. ${ }^{13-18}$ Constructing specific chemical binding motives and frustrated Lewis pairs (FLP) are two main routes for the activation of molecules such as $\mathrm{N}_{2}$ or $\mathrm{CO}_{2}$ due to strong substrate polarization, which usually improves the corresponding electrocatalytic performance. ${ }^{19-22}$ Another possible source of significant catalytic activity in graphene-based materials are point defects at grain boundaries. Such point defects can lead to the presence of a large number of unpaired electrons. This can even cause macroscopic ferromagnetism ${ }^{23-25}$ or can be the reason for catalytic activity. ${ }^{26}$ Doping graphene-based materials with $\mathrm{B}$ and $\mathrm{N}$ in fact significantly enhances the density of grain boundaries because of the preferred formation of nanoscale B$\mathrm{N}$ domains/grains. ${ }^{27-29}$ Although these principles are in general known and accepted, they have not yet been transferred to porous carbonaceous materials.

One electrocatalytic reaction that has recently received significant attention is the electrochemical $\mathrm{N}_{2}$ reduction reaction (NRR), which is a potential alternative to the

Received: September 20, 2019

Accepted: November 5, 2019

Published: November 5, 2019 
traditional Haber-Bosch process that can be driven by renewable electricity at ambient conditions instead of high temperature and pressure. ${ }^{30-34}$ In NRR, hydrogen is formally created from water instead of coal or methane, and thus no $\mathrm{CO}_{2}$ is created as a side product in this process. Furthermore, NRR can be performed anywhere because it is geographically not linked to hydrogen production. This "decentral production" does eliminate the necessity to transport produced ammonia and fertilizer over long distances and also simplifies production on demand. However, considering the inertness of $\mathrm{N}_{2}$ molecules and the demanding six-electron transfer, strong competition from the hydrogen evolution reaction (HER) remains a major problem. To implement NRR on large scale in the future, catalysts with high selectivity, but at the same time low costs and low overpotentials, are required. ${ }^{35-39}$ Although metal-free catalysts for NRR have been developed, their Faradaic efficiency (FE) and $\mathrm{NH}_{3}$ production rate still remain limited. $^{40}$

Electrocatalysis is most rewarding when not only the reductive half-reaction but also the coupled oxidative halfreaction creates a valuable product. Instead of coupling NRR with the oxygen evolution reaction (OER), selective oxidation of other substances such as biomass would be a more valuable reverse process in a full cell. ${ }^{41}$ However, these reactions are also far from simple and have high requirements on the catalysts as well. Biomass is a sustainable non-fossil-based carbon source and can serve as an alternative feedstock for the chemical industry. ${ }^{42-45}$ Among different biomass-derived platform molecules, 2,5-furandicarboxylic acid (FDCA) is particularly important as it is a widely applied starting monomer or intermediate for different polymeric materials and can potentially replace terephthalic acid. ${ }^{46-48}$ Currently, FDCA is mainly produced from the oxidation of 5-hydroxymethylfurfural (HMF) with $\mathrm{O}_{2}$ under high pressure, while HMF is derived from cellulosic biomass. ${ }^{49,50}$ Electrocatalytic oxidation of HMF under ambient conditions is possible as well but requires the use of metal-based catalysts. ${ }^{51-54}$

In this work, $\mathrm{N}$ and $\mathrm{B}$ codoped porous carbon with abundant point defects and polar pore wall structure, in which positively charged $\mathrm{B}$ atoms act as electron acceptors together with negatively charged $\mathrm{N}$ atoms as electron donors, is fabricated. The as-obtained BNC material was applied for electrochemical NRR with a high $\mathrm{FE}$ of $15.2 \%$ and a $\mathrm{NH}_{3}$ production rate of $21.3 \mu \mathrm{g} \mathrm{h}^{-1} \mathrm{mg}^{-1}$. Besides, this material was used as the first metal-free electrocatalyst for HMF oxidation with a FDCA yield of $57 \%$ at $71 \%$ conversion after a reaction time of $6 \mathrm{~h}$.

\section{RESULTS AND DISCUSSION}

In a typical synthesis of $\mathrm{B}$ and $\mathrm{N}$ codoped carbon, a mixture of melamine, L-cysteine, and boric acid as precursors underwent pyrolysis at high temperature. To tune the amount and binding structure of the doped atoms, different mass ratios of melamine to L-cysteine to boric acid were mixed, and as-obtained products were denoted as $\mathrm{NC}, \mathrm{BNC}-1$, and $\mathrm{BNC}-2$ with the ratio of 2:1:0, 2:1:0.2, and 2:1:1, respectively. During the pyrolysis, the reactants were first pyrolyzed at $600{ }^{\circ} \mathrm{C}$ to form B-doped $\mathrm{C}_{3} \mathrm{~N}_{4}$, which was further heated to $1000{ }^{\circ} \mathrm{C}$ to obtain BNC (Figure 1a). ${ }^{15,55}$ Transmission electron microscopy (TEM) images of BNC-2 (Figure $1 \mathrm{~b}, \mathrm{c}$ ) show a morphology of interconnected nanoribbons with uniform but defect-rich nanoporous structure. The uniform presence of different elements $\mathrm{B}, \mathrm{C}$, and $\mathrm{N}$ is demonstrated by electrons energy loss
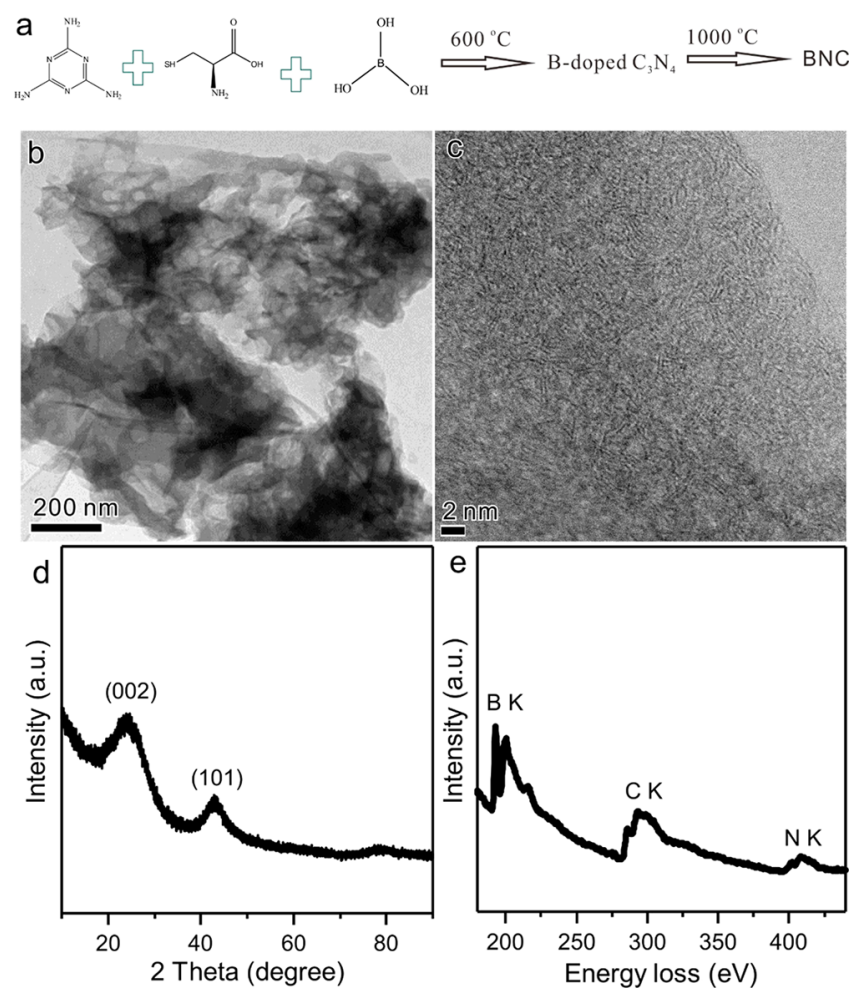

Figure 1. (a) Synthesis processes of $\mathrm{N}$ and $\mathrm{B}$ codoped carbon. (b) Representative TEM image, (c) HRTEM image, (d) XRD pattern, and (e) EELS spectrum of BNC-2.

spectroscopy (EELS) elemental mapping (Figure S1). A comparable structure is observed for NC and BNC-1 (Figure S2). The individual ribbons of NC appear thinner but larger in the plane, which indicates that the codoping of $\mathrm{N}$ and $\mathrm{B}$ can improve the interaction (stacking) between the single graphene-like layers and introduces more grain boundaries at the same time. Scanning electron microscopy (SEM) images (Figure S3) also exhibit a rather dense appearance of the BCN samples when directly compared to the rather graphene-like NC material, in accordance with TEM results. X-ray diffraction (XRD) (Figure 1d) patterns of BNC-2 show only broad peaks corresponding to (002) and (101) reflections at $26^{\circ}$ and $44^{\circ}$, respectively, which are also present in NC and BNC-1 (Figure S4). This indicates that the structure is mainly amorphous, which is typical for nanoporous carbon materials, and the absence of crystalline $\mathrm{BN}$ in the as-obtained samples. The acquired electron energy loss spectrum (EELS) (Figure 1e) confirms the coexistence of $\mathrm{B}, \mathrm{C}$, and $\mathrm{N}$ in the $\mathrm{BCN}-2$, with the K-edge absorptions at 191, 284, and $401 \mathrm{eV}$, respectively.

$\mathrm{X}$-ray photoelectron spectroscopy (Figure S5) was also conducted to investigate the chemical compositions of the samples. With increased addition of boric acid, the doping level of $\mathrm{B}$ and $\mathrm{N}$ increases (Table S1); i.e., $\mathrm{B}$ helps to keep $\mathrm{N}$ in the structures, presumably via $\mathrm{B}-\mathrm{N}$ bonds. XPS spectra of $\mathrm{N} 1 \mathrm{~s}$ were then deconvoluted to elucidate the detailed binding motives (Figure 2a). In BNC-1 and BNC-2, the four characteristic peaks centered at 398.1, 398.5, 399.7, and $400.8 \mathrm{eV}$ can be ascribed to pyridinic N, N bonded to B atoms, pyrrolic $\mathrm{N}$, and quaternary $\mathrm{N}$ atoms, respectively. The content of electron-rich/Lewis basic $\mathrm{N}$ atoms is apparently higher in BNC-2. ${ }^{56,57} \mathrm{~N}$ 1s spectra of B-free NC show the presence of pyridinic $\mathrm{N}$, pyrrolic $\mathrm{N}$, quaternary $\mathrm{N}$, and oxidized $\mathrm{N}$ atoms. ${ }^{58}$ The high-resolution B 1s spectra show three obvious peaks 

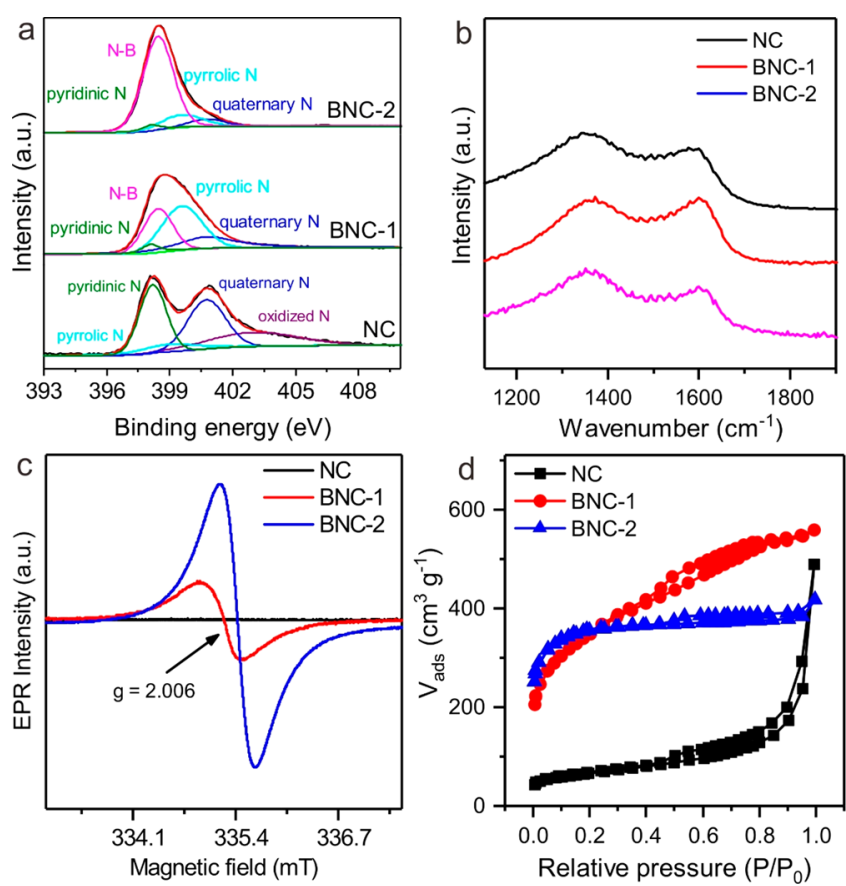

Figure 2. (a) High-resolution N 1s XPS spectra, (b) Raman spectra, (c) EPR spectra, and (d) $\mathrm{N}_{2}$ physisorption isotherms (at $-196{ }^{\circ} \mathrm{C}$ ) of NC, BNC-1, and BNC-2.

corresponding to $\mathrm{B}-\mathrm{O}, \mathrm{B}-\mathrm{N}$, and $\mathrm{B}-\mathrm{C}$ species (Figure $\mathrm{S} 6$ ) in BNC-1 and BNC-2. ${ }^{59}$ The content of electron-deficient/Lewis acidic $\mathrm{B}$ atoms is also apparently higher in BNC-2. The successful fabrication of $\mathrm{B}-\mathrm{N}$ bonds in $\mathrm{BNC}-2$ is also demonstrated by Fourier transform infrared spectra with obvious peaks located at $1380 \mathrm{~cm}^{-1}$ (Figure S7), which can be attributed to out-of-plane stretching of $\mathrm{B}-\mathrm{N}-\mathrm{B}$ bonds. ${ }^{60}$
Raman spectra (Figure 2b) show two characteristic peaks at $\sim 1598$ and $\sim 1338 \mathrm{~cm}^{-1}$, which can be assigned to the socalled disordered (D) and graphite (G) bands of carbon, respectively. The low intensity of both bands indicates the very defective carbon structure in the materials because codoping of $\mathrm{N}$ and $\mathrm{B}$ heteroatoms creates abundant point defects and possible also vibrational dissymmetry in the $\mathrm{sp}^{2}$ carbon structure. Electron paramagnetic resonance (EPR) spectra show an obvious EPR signal for BNC with a $g$ value of 2.006, and the signal intensity increases with the doping level of $\mathrm{N}$ and $\mathrm{B}$, while there is almost no EPR signal for NC (Figure 2c). This EPR signal can be attributed to the presence of plenty of unpaired electrons due to point defects at grain boundaries in BNC. ${ }^{61-63}$ In addition, FLPs can possibly be formed from nonsaturated $\mathrm{B}$ and $\mathrm{N}$ atoms near these defects, providing the targeted-for unique advantages for the activation of small molecules in electrocatalysis. These properties are absent in $\mathrm{NC}$ and less pronounced in BNC-1, as also reflected in the lower intensity of the EPR signals.

$\mathrm{N}_{2}\left(-196^{\circ} \mathrm{C}\right)$ physisorption experiments were performed to analyze the textural properties of the $\mathrm{BNC}$ and $\mathrm{NC}$ materials (Figure 2d). Compared with NC, doping of B and N in BNC-1 and BNC-2 results in significantly increased specific surface areas (SSAs) (Table S2). Note that most nanopores indeed rely on edge termination of the covalent $\mathrm{BNC}$ sheets; i.e., these are the preferred locations of unpaired electrons and FLP motifs. The shapes of the isotherms at different relative pressures also represent specific hierarchical pore characters. The higher $\mathrm{N}_{2}$ uptake at lower pressure indicates a high content of narrow micropores in BNC-2, especially when compared to BNC-1. In contrast, there is only a small volume of micropores and mesopores but a higher macropore volume and external surface area in NC. This is typical for sintered porous carbons which in general loose micropores due to
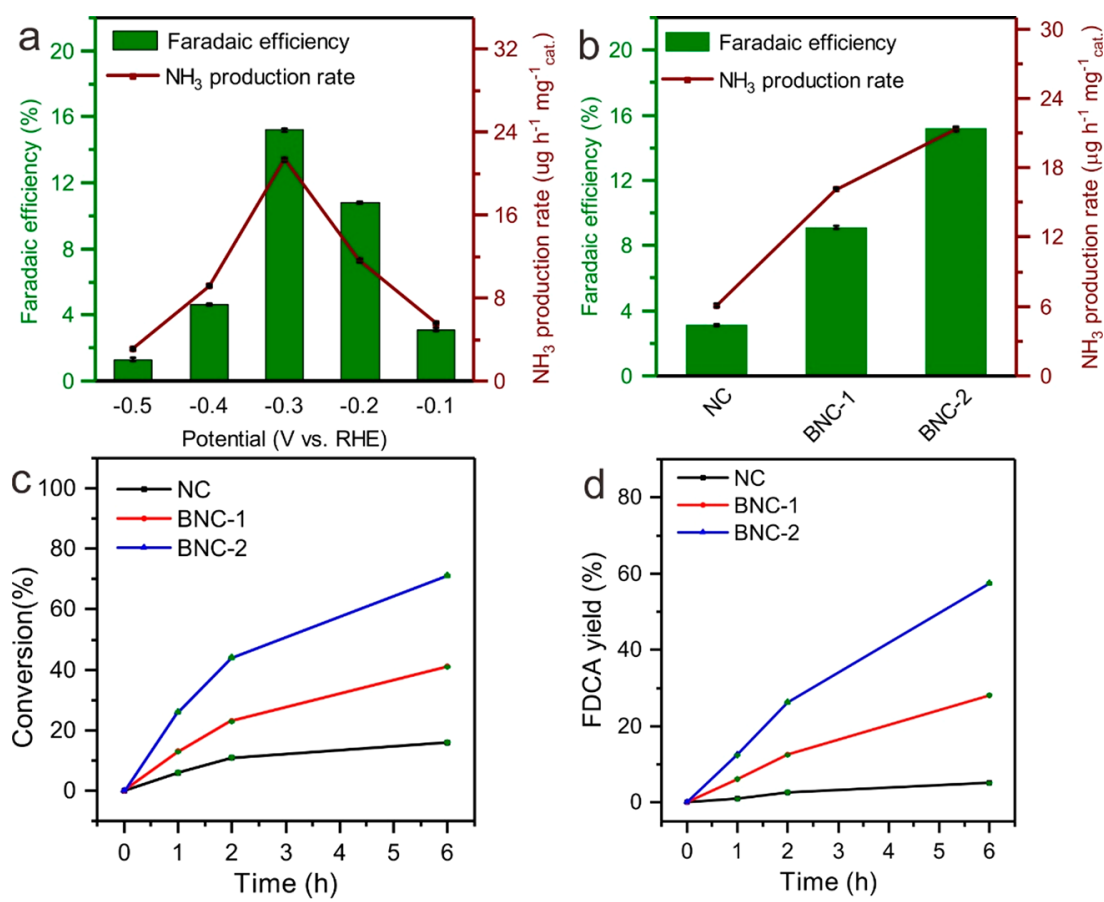

Figure 3. (a) $\mathrm{FE}$ and $\mathrm{NH}_{3}$ production rate of $\mathrm{BNC}-2$ electrode at different given potentials. (b) Comparison of $\mathrm{FE}$ and $\mathrm{NH}_{3}$ production rate at a potential of $-0.3 \mathrm{~V}$ vs RHE for NC, BNC-1, and BNC-2. (c) HMF conversion and (d) FDCA yield over the 6 h chronoamperometry test of NC, BNC-1, and BNC-2 electrode, respectively. 
covalent rearrangement and sintering at higher temperatures. $\mathrm{BN}$ motifs obviously improve the stability of edge terminations against sintering. All that is confirmed by the pore size and pore volume distribution curves (Figure S8). Therefore, it can be concluded that codoping of $\mathrm{B}$ and $\mathrm{N}$ can create a hierarchical nanoporous architecture, and the $\mathrm{BN}$ content has a significant effect on the pore structure and its stability, which provides innate advantages for the further catalytic applications.

In view of the unique structure of $\mathrm{N}$ and $\mathrm{B}$ codoped carbon, including porosity and high heteroatom doping level as well as unpaired electrons and high oxidation potential, their electrocatalytic applications were studied. The electrochemical NRR performance of BNC-2 was first tested with a three-electrode system. The comparison of linear sweep voltammetry (LSV) curves under $\mathrm{Ar}$ - and $\mathrm{N}_{2}$-saturated electrolyte solution indicates an obvious current response of the BNC-2 electrode toward $\mathrm{N}_{2}$ (Figure S9a). Chronoamperometry tests were then conducted under different given potentials (Figure S9b), while the corresponding $\mathrm{FE}$ and $\mathrm{NH}_{3}$ production rates were quantified from the $\mathrm{NH}_{4}{ }^{+}$calibration curve (Figure S10). A maximum $\mathrm{FE}$ of $15.2 \%$ with a comparably high $\mathrm{NH}_{3}$ production rate of $21.3 \mu \mathrm{g} \mathrm{h}^{-1} \mathrm{mg}^{-1}$ can be achieved at a potential of $-0.3 \mathrm{~V}$ vs RHE (Figure 3a). At more negative given potentials, $\mathrm{FE}$ and $\mathrm{NH}_{3}$ production rates both decrease mainly due to the fact that HER turns into the dominant process. ${ }^{64}$ Optical images and UV-vis spectra show that the BNC-2 catalyst does selectively produce $\mathrm{NH}_{3}$. The solutions have been tested for $\mathrm{N}_{2} \mathrm{H}_{4}$ as one possible byproduct, and $\mathrm{N}_{2} \mathrm{H}_{4}$ cannot be detected, independent of the applied potentials (Figure S11). In addition to high activity, excellent stability is also required for a practical NRR catalyst. As shown in the recycling test (Figure $\mathrm{S} 12 \mathrm{a}$ ), $\mathrm{FE}$ and $\mathrm{NH}_{3}$ production rates remain almost constant (Figure $\mathrm{S} 12 \mathrm{~b}$ ), and the long-term chronoamperometry test also exhibits good current stability of BNC-2 (Figure S13). TEM images and XPS spectra acquired for BNC-2 material after the cycle test demonstrate the structural stability (Figure S14). To exclude $\mathrm{NH}_{3}$ to come from other nitrogen sources, some control experiments were conducted by measuring the $\mathrm{NH}_{4}^{+}$concentration within the pure electrolyte before the test, under open circuit potential, and by using pure carbon paper as the catalyst at the potential of $-0.3 \mathrm{~V}$ vs RHE. As shown in the UV spectra, no $\mathrm{NH}_{4}{ }^{+}$has been detected in those control experiments (Figure S15a) as well as under Ar-saturated electrolyte at different given potentials (Figure S15b). In addition, based on the rigorous protocol for $\mathrm{NH}_{3}$ synthesis, ${ }^{65}$ an ${ }^{15} \mathrm{~N}$ isotopic labeling experiment was performed (Figure S16). The ${ }^{1} \mathrm{H}$ nuclear magnetic resonance $\left({ }^{1} \mathrm{H} \mathrm{NMR}\right)$ spectra of standard samples of ${ }^{14} \mathrm{NH}_{4}{ }^{+}$and ${ }^{15} \mathrm{NH}_{4}^{+}$exhibit a triplet coupling and double coupling, respectively. Through comparison, the feeding gas of ${ }^{14} \mathrm{~N}_{2}$ and ${ }^{15} \mathrm{~N}_{2}$ produces ${ }^{14} \mathrm{NH}_{4}^{+}$and ${ }^{15} \mathrm{NH}_{4}^{+}$as the final product, respectively. Therefore, it can be seen as proven that the $\mathrm{NH}_{4}{ }^{+}$in the electrolyte is generated via NRR catalyzed by BNC-2. To highlight the influence of codoping and porosity, $\mathrm{NC}$ and $\mathrm{BNC}-1$ were also tested and compared with BCN-2 (Figure $3 \mathrm{~b}$ ). Both materials exhibit a significantly lower FE and $\mathrm{NH}_{3}$ production rate.

Another requirement for the large-scale implementation of electrochemical NRR would be the coupling with a suitable value generating oxidation process on the opposite electrode in a symmetrical full cell. In addition to the electroreduction reaction, the ability of as-obtained samples to act as an oxidation catalyst was also tested. Compared with the electrooxidation of water producing oxygen, which is abundantly available from cryogenic distillation of air, selective oxidation of biomass by electricity is promising to synthesize high-value chemical compounds. Therefore, the electrooxidation of HMF was studied as a second application using $\mathrm{BNC}$ and NC materials as catalysts.

From the LSV curves of BNC-2 with and without the addition of $5 \mathrm{mM}$ of HMF in $0.1 \mathrm{M} \mathrm{NaOH}$ (Figure S14a), it can be seen that current densities dramatically increase after adding HMF, indicating that the materials exhibit obvious catalytic activity for HMF oxidation. In the absence of HMF, there is also an anodic current due to the water oxidation to $\mathrm{O}_{2}$, which is the main competing reaction for HMF oxidation (in a comparable way as HER is for NRR). ${ }^{66,67}$ Similarly, BNC-1 also shows obvious current response for HMF oxidation (Figure S14b). On the contrary, the current densities after adding HMF only slightly increase for NC and at higher overpotentials (Figure S14c). In the absence of HMF, the current densities generated by the NC electrode are much higher when comparing to the BNC electrode, which shows that $\mathrm{NC}$ is a more favorable catalyst for water oxidation/OER, while $\mathrm{BCN}$ is not. There are several possible intermediates during the oxidation of HMF to FDCA (Scheme S1), such as 2,5-diformylfuran (DFF), 5-formyl-2-furancarboxylic acid (FFCA), and 5-hydroxymethyl-2-furancarboxylic acid (HMFCA). ${ }^{68}$ Therefore, chronoamperometry tests were further performed to investigate the HMF conversion and FDCA selectivity over time. At a potential of $1.9 \mathrm{~V}$ vs RHE and after $6 \mathrm{~h}, 71 \%$ of HMF was successfully converted at the BNC2 electrode, which largely surpasses the catalytic activity of NC and BNC-1 (Figure 3c). BNC-2 also provides a desirable FDCA yield of $57 \%$ (Figure 3d). Carbon paper without catalyst loading does not exhibit any activity for HMF oxidation (Figure S15). In addition, the stability test of BNC-2 for HMF oxidation (Figure S16) shows that the current densities first decrease due to the consumption of reactants and then recover immediately after readdition of HMF. After four times, BNC-2 can still provide fast and sensitive response toward HMF addition, implying good stability and the absence of irreversible processes on the electrode.

Based on the above analysis and comparisons, BNC-2 exhibits the best catalytic performances, both for nitrogen reduction and for biomass oxidation. Following the activitystructure relationships, the possible active sites for this catalysis must be discussed. First, it has been recently reported that B$\mathrm{N}$ bonds can act as the active sites for electrochemical NRR. ${ }^{22}$ As can be seen from XPS results, the excellent activity of BNC2 indeed goes with a higher content of $\mathrm{B}-\mathrm{N}$ bonds. Maybe more importantly, $\mathrm{B}$ and $\mathrm{N}$ atoms near defects could act as a FLP-like structure with positively polarized (electrophilic) B atoms and negatively polarized (nucleophilic) $\mathrm{N}$ atoms, and thus the reactants $\mathrm{N}_{2}$ and HMF could be effectively activated by strong polarization on top of these structural motives. ${ }^{39}$ Furthermore, point defects at the grain boundaries between $\mathrm{B}-\mathrm{N}$ and graphitic domains can lead to high catalytic activity because the unpaired electrons at such sites will provide binding sites for the substrate molecules and electron transfer activation. From a textural point of view, as a result of the higher nanoporosity, BNC-2 also exhibits higher electrochemical surface area (ECSA) according to capacitance measurements (Figure S17). This is of particular importance 

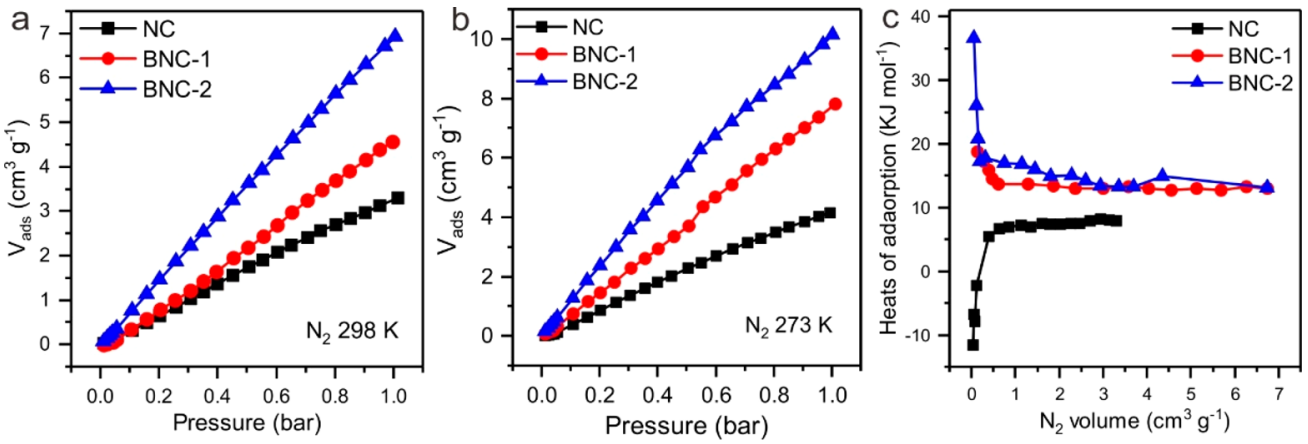

Figure 4. $\mathrm{N}_{2}$ adsorption isotherms measured at (a) $298 \mathrm{~K}$ and (b) $273 \mathrm{~K}$ for NC, BNC-1, and BNC-2 materials. (c) Heat of $\mathrm{N}_{2}$ adsorption for NC, BNC-1, and BNC-2 materials.

for the catalytic conversion of larger molecules such as HMF as they have to have access to the entire internal surface of the catalyst particles deposited on the electrodes.

As mentioned above, codoping of $\mathrm{N}$ and $\mathrm{B}$ creates a porous structure with high SSA, which can be favorable for adsorption and activation of reactants as well as for electron/mass transfer. $\mathrm{N}_{2}$ adsorption experiments at $298 \mathrm{~K}$ show that BNC-2 can indeed adsorb a higher volume of $\mathrm{N}_{2}$ even at room temperature, compared with $\mathrm{NC}$ and BNC-1 (Figure 4a). $\mathrm{N}_{2}$ adsorption at $273 \mathrm{~K}$ was also tested (Figure $4 \mathrm{~b}$ ) and exhibits the same trend. Based on those two data sets, the heat of adsorption $\left(Q_{s t}\right)$ for $\mathrm{N}_{2}$ was estimated (Figure $4 \mathrm{c}$ ). The $Q_{\mathrm{st}}$ values at low $\mathrm{N}_{2}$ uptakes come with a rather high experimental error, and a comparison at higher volumes of adsorbed $\mathrm{N}_{2}$ is more reliable. Indeed, the unusual high value of $Q_{s t}$ indicates strong affinity between $\mathrm{BCN}-2$ and $\mathrm{N}_{2}$ molecules. This quantifies the $\mathrm{N}_{2}$ polarization beyond van der Waals binding and activation which is certainly one source of its higher NRR activity.

\section{CONCLUSION}

In summary, a novel $\mathrm{N}$ and $\mathrm{B}$ codoped carbon catalyst with porous structure has been synthesized from simple precursors. The introduction of $\mathrm{N}$ and $\mathrm{B}$ heteroatoms leads to the construction of $\mathrm{N}-\mathrm{B}$ motives and frustrated Lewis pairs in a microporous architecture which is also rich in point defects. The latter can improve the strength of adsorption of reactants $\left(\mathrm{N}_{2}\right.$ and $\mathrm{HMF}$ ) and thus their activation. As a result, BNC-2 exhibits a desirable electrochemical NRR and HMF oxidation performance. HMF oxidation has only been shown exemplarily here and that the catalytic concept is general and can also be applied for oxidation reactions. A further increase of the boron content and careful balancing of the elemental composition provides room for further enhancement of these NRR catalysts. Gas adsorption experiments support the unusually strong binding and activation of $\mathrm{N}_{2}$ and might serve as a simple descriptor to relate structure and catalytic activity. We believe that this work provides novel and deep insights into the rational design and the origin of activity in metal-free electrocatalysts and enables a physically viable discussion of the active motives as well as the search for their further applications.

\section{ASSOCIATED CONTENT}

\section{S Supporting Information}

The Supporting Information is available free of charge on the ACS Publications website at DOI: 10.1021/acsaem.9b01852.
Experimental details, materials characterizations, and catalytic tests (PDF)

\section{AUTHOR INFORMATION}

\section{Corresponding Authors}

*E-mail: martin.oschatz@mpikg.mpg.de.

*E-mail: qing.qin@mpikg.mpg.de.

ORCID $\odot$

Q. Qin: 0000-0001-5632-1100

M. Schmallegger: 0000-0001-6097-8252

Georg Gescheidt: 0000-0002-6827-4337

M. Antonietti: 0000-0002-8395-7558

Notes

The authors declare no competing financial interest.

\section{ACKNOWLEDGMENTS}

We thank Dr. Heike Runge and Jianrui Zhang for the SEM tests. We thank Jose Mendoza Mesa for the instruction into the HPLC technique. This work was funded by the Deutsche Forschungsgemeinschaft (DFG, German Research Foundation) under Germany's Excellence Strategy-EXC 2008/1 (UniSysCat)-390540038.

\section{REFERENCES}

(1) Chen, S.; Duan, J. J.; Ran, J. R.; Jaroniec, M.; Qiao, S. Z. Ndoped graphene film-confined nickel nanoparticles as a highly efficient three-dimensional oxygen evolution electrocatalyst. Energy Environ. Sci. 2013, 6 (12), 3693-3699.

(2) Gong, K.; Du, F.; Xia, Z.; Durstock, M.; Dai, L. Nitrogen-doped carbon nanotube arrays with high electrocatalytic activity for oxygen reduction. Science 2009, 323 (5915), 760-764.

(3) Ma, T. Y.; Ran, J.; Dai, S.; Jaroniec, M.; Qiao, S. Z. Phosphorusdoped graphitic carbon nitrides grown in situ on carbon-fiber paper: flexible and reversible oxygen electrodes. Angew. Chem., Int. Ed. 2015, 54 (15), 4646-50.

(4) Hua, Y. Q.; Jiang, T. T.; Wang, K.; Wu, M. M.; Song, S. Q.; Wang, Y.; Tsiakaras, P. Efficient Pt-free electrocatalyst for oxygen reduction reaction: Highly ordered mesoporous $\mathrm{N}$ and $\mathrm{S}$ co-doped carbon with saccharin as single-source molecular precursor. Appl. Catal., B 2016, 194, 202-208.

(5) Liu, Y.; Shen, Y.; Sun, L.; Li, J.; Liu, C.; Ren, W.; Li, F.; Gao, L.; Chen, J.; Liu, F.; Sun, Y.; Tang, N.; Cheng, H. M.; Du, Y. Elemental superdoping of graphene and carbon nanotubes. Nat. Commun. 2016, 7, 10921 .

(6) Qian, Y. H.; Hu, Z. G.; Ge, X. M.; Yang, S. L.; Peng, Y. W.; Kang, Z. X.; Liu, Z. L.; Lee, J. Y.; Zhao, D. A metal-free ORR/OER bifunctional electrocatalyst derived from metal-organic frameworks for rechargeable Zn-Air batteries. Carbon 2017, 111, 641-650. 
(7) Zhao, Y.; Nakamura, R.; Kamiya, K.; Nakanishi, S.; Hashimoto, K. Nitrogen-doped carbon nanomaterials as non-metal electrocatalysts for water oxidation. Nat. Commun. 2013, 4, 2390.

(8) Cha, H. G.; Choi, K. S. Combined biomass valorization and hydrogen production in a photoelectrochemical cell. Nat. Chem. 2015, 7 (4), 328-33.

(9) $\mathrm{Qu}$, K. G.; Zheng, Y.; Dai, S.; Qiao, S. Z. Graphene oxidepolydopamine derived $\mathrm{N}$, S-codoped carbon nanosheets as superior bifunctional electrocatalysts for oxygen reduction and evolution. Nano Energy 2016, 19, 373-381.

(10) Antonietti, M.; Oschatz, M. The Concept of "Noble, Heteroatom-Doped Carbons", Their Directed Synthesis by Electronic Band Control of Carbonization, and Applications in Catalysis and Energy Materials. Adv. Mater. 2018, 30 (21), 1706836.

(11) Zhang, J.; Zhao, Z.; Xia, Z.; Dai, L. A metal-free bifunctional electrocatalyst for oxygen reduction and oxygen evolution reactions. Nat. Nanotechnol. 2015, 10 (5), 444-52.

(12) Lu, Z. Y.; Wang, J.; Huang, S. F.; Hou, Y. L.; Li, Y. G.; Zhao, Y. P.; Mu, S. C.; Zhang, J. J.; Zhao, Y. F. N,B-codoped defect-rich graphitic carbon nanocages as high performance multifunctional electrocatalysts. Nano Energy 2017, 42, 334-340.

(13) Zhao, C. J.; Zhang, S. B.; Han, M. M.; Zhang, X.; Liu, Y. Y.; Li, W. Y.; Chen, C.; Wang, G. Z.; Zhang, H. M.; Zhao, H. J. Ambient Electrosynthesis of Ammonia on a Biomass-Derived Nitrogen-Doped Porous Carbon Electrocatalyst: Contribution of Pyridinic Nitrogen. ACS Energy Lett. 2019, 4 (2), 377-383.

(14) Ghausi, M. A.; Xie, J.; Li, Q.; Wang, X.; Yang, R.; Wu, M.; Wang, Y.; Dai, L. $\mathrm{CO}_{2}$ Overall Splitting by a Bifunctional Metal-Free Electrocatalyst. Angew. Chem., Int. Ed. 2018, 57 (40), 13135-13139.

(15) Liu, S.; Yang, H. B.; Huang, X.; Liu, L. H.; Cai, W. Z.; Gao, J. J.; Li, X. N.; Zhang, T.; Huang, Y. Q.; Liu, B. Identifying Active Sites of Nitrogen-Doped Carbon Materials for the $\mathrm{CO}_{2}$ Reduction Reaction. Adv. Funct. Mater. 2018, 28 (21), 1800499.

(16) Zhang, J.; Dai, L. Nitrogen, Phosphorus, and Fluorine Tridoped Graphene as a Multifunctional Catalyst for Self-Powered Electrochemical Water Splitting. Angew. Chem., Int. Ed. 2016, 55 (42), 13296-13300.

(17) Zhou, Y. J.; Sun, Y.; Wang, H. B.; Zhu, C.; Gao, J.; Wu, D.; Huang, H.; Liu, Y.; Kang, Z. H. A nitrogen and boron co-doped metal-free carbon electrocatalyst for an efficient oxygen reduction reaction. Inorg. Chem. Front. 2018, 5 (11), 2985-2991.

(18) Zhang, J.; Sun, Y. M.; Zhu, J. W.; Kou, Z. K.; Hu, P.; Liu, L.; Li, S. Z.; Mu, S. C.; Huang, Y. H. Defect and pyridinic nitrogen engineering of carbon-based metal-free nanomaterial toward oxygen reduction. Nano Energy 2018, 52, 307-314.

(19) Grimme, S.; Kruse, H.; Goerigk, L.; Erker, G. The mechanism of dihydrogen activation by frustrated Lewis pairs revisited. Angew. Chem., Int. Ed. 2010, 49 (8), 1402-5.

(20) Momming, C. M.; Otten, E.; Kehr, G.; Frohlich, R.; Grimme, S.; Stephan, D. W.; Erker, G. Reversible metal-free carbon dioxide binding by frustrated Lewis pairs. Angew. Chem., Int. Ed. 2009, 48 (36), 6643-6.

(21) Stephan, D. W. "Frustrated Lewis pairs": a concept for new reactivity and catalysis. Org. Biomol. Chem. 2008, 6 (9), 1535-9.

(22) Chen, C.; Yan, D.; Wang, Y.; Zhou, Y.; Zou, Y.; Li, Y.; Wang, S. BN Pairs Enriched Defective Carbon Nanosheets for Ammonia Synthesis with High Efficiency. Small 2019, 15 (7), e1805029.

(23) Yazyev, O. V.; Helm, L. Defect-induced magnetism in graphene. Phys. Rev. B: Condens. Matter Mater. Phys. 2007, 75 (12), 125408 .

(24) Zhou, J.; Wang, Q.; Sun, Q.; Chen, X. S.; Kawazoe, Y.; Jena, P. Ferromagnetism in semihydrogenated graphene sheet. Nano Lett. 2009, 9 (11), 3867-70.

(25) Cervenka, J.; Katsnelson, M. I.; Flipse, C. F. J. Roomtemperature ferromagnetism in graphite driven by two-dimensional networks of point defects. Nat. Phys. 2009, 5 (11), 840-844.

(26) Nichols, J. A.; Saito, H.; Deck, C.; Bandaru, P. R. Artificial introduction of defects into vertically aligned multiwalled carbon nanotube ensembles: Application to electrochemical sensors. J. Appl. Phys. 2007, 102 (6), 064306.

(27) Bepete, G.; Voiry, D.; Chhowalla, M.; Chiguvare, Z.; Coville, N. $\mathrm{J}$. Incorporation of small $\mathrm{BN}$ domains in graphene during CVD using methane, boric acid and nitrogen gas. Nanoscale 2013, 5 (14), 65527.

(28) Shinde, P. P.; Kumar, V. Direct band gap opening in graphene by BN doping: Ab initio calculations. Phys. Rev. B: Condens. Matter Mater. Phys. 2011, 84 (12), 125401.

(29) Xu, B.; Lu, Y. H.; Feng, Y. P.; Lin, J. Y. Density functional theory study of $\mathrm{BN}$-doped graphene superlattice: Role of geometrical shape and size. J. Appl. Phys. 2010, 108 (7), 073711.

(30) van der Ham, C. J.; Koper, M. T.; Hetterscheid, D. G. Challenges in reduction of dinitrogen by proton and electron transfer. Chem. Soc. Rev. 2014, 43 (15), 5183-91.

(31) Licht, S.; Cui, B.; Wang, B.; Li, F. F.; Lau, J.; Liu, S. Ammonia synthesis. Ammonia synthesis by $\mathrm{N}_{2}$ and steam electrolysis in molten hydroxide suspensions of nanoscale $\mathrm{Fe}_{2} \mathrm{O}_{3}$. Science 2014, 345 (6197), 637-40.

(32) Chu, S.; Majumdar, A. Opportunities and challenges for a sustainable energy future. Nature 2012, 488 (7411), 294-303.

(33) Erisman, J. W.; Sutton, M. A.; Galloway, J.; Klimont, Z.; Winiwarter, W. How a century of ammonia synthesis changed the world. Nat. Geosci. 2008, 1 (10), 636-639.

(34) Qin, Q.; Zhao, Y.; Schmallegger, M.; Heil, T.; Schmidt, J.; Walczak, R.; Gescheidt-Demner, G.; Jiao, H.; Oschatz, M. Enhanced electrocatalytic $\mathrm{N}_{2}$ reduction via partial anion substitution in titanium oxide-carbon composites. Angew. Chem., Int. Ed. 2019, 58, 1310113106.

(35) Montoya, J. H.; Tsai, C.; Vojvodic, A.; Norskov, J. K. The Challenge of Electrochemical Ammonia Synthesis: A New Perspective on the Role of Nitrogen Scaling Relations. ChemSusChem 2015, 8 (13), 2180-6.

(36) Singh, A. R.; Rohr, B. A.; Schwalbe, J. A.; Cargnello, M.; Chan, K.; Jaramillo, T. F.; Chorkendorff, I.; Nørskov, J. K. Electrochemical Ammonia Synthesis-The Selectivity Challenge. ACS Catal. 2017, 7 (1), 706-709.

(37) Suryanto, B. H. R.; Du, H. L.; Wang, D. B.; Chen, J.; Simonov, A. N.; MacFarlane, D. R. Challenges and prospects in the catalysis of electroreduction of nitrogen to ammonia. Nat. Catal. 2019, 2 (4), 290-296.

(38) Wang, S. Y.; Ichihara, F.; Pang, H.; Chen, H.; Ye, J. H. Nitrogen Fixation Reaction Derived from Nanostructured Catalytic Materials. Adv. Funct. Mater. 2018, 28 (50), 1803309.

(39) Qin, Q.; Heil, T.; Antonietti, M.; Oschatz, M. Single-Site Gold Catalysts on Hierarchical N-Doped Porous Noble Carbon for Enhanced Electrochemical Reduction of Nitrogen. Small Methods 2018, 2 (12), 1800202.

(40) Huang, H.; Xia, L.; Cao, R.; Niu, Z.; Chen, H.; Liu, Q.; Li, T.; Shi, X.; Asiri, A. M.; Sun, X. A Biomass-Derived Carbon-Based Electrocatalyst for Efficient $\mathrm{N}_{2}$ Fixation to $\mathrm{NH}_{3}$ under Ambient Conditions. Chem. - Eur. J. 2019, 25 (8), 1914-1917.

(41) Antonietti, M.; Savateev, A. Splitting Water by Electrochemistry and Artificial Photosynthesis: Excellent Science but a Nightmare of Translation? Chem. Rec. 2018, 18 (7-8), 969-972.

(42) Besson, M.; Gallezot, P.; Pinel, C. Conversion of biomass into chemicals over metal catalysts. Chem. Rev. 2014, 114 (3), 1827-70.

(43) Huber, G. W.; Iborra, S.; Corma, A. Synthesis of transportation fuels from biomass: chemistry, catalysts, and engineering. Chem. Rev. 2006, 106 (9), 4044-98.

(44) Chatterjee, C.; Pong, F.; Sen, A. Chemical conversion pathways for carbohydrates. Green Chem. 2015, 17 (1), 40-71.

(45) Binder, J. B.; Raines, R. T. Simple chemical transformation of lignocellulosic biomass into furans for fuels and chemicals. J. Am. Chem. Soc. 2009, 131 (5), 1979-85.

(46) Tong, X. L.; Ma, Y.; Li, Y. D. Biomass into chemicals: Conversion of sugars to furan derivatives by catalytic processes. Appl. Catal., A 2010, 385 (1-2), 1-13. 
(47) van Putten, R. J.; van der Waal, J. C.; de Jong, E.; Rasrendra, C. B.; Heeres, H. J.; de Vries, J. G. Hydroxymethylfurfural, a versatile platform chemical made from renewable resources. Chem. Rev. 2013, 113 (3), 1499-597.

(48) Gandini, A.; Silvestre, A. J. D.; Neto, C. P.; Sousa, A. F.; Gomes, M. The Furan Counterpart of Poly(ethylene terephthalate): An Alternative Material Based on Renewable Resources. J. Polym. Sci., Part A: Polym. Chem. 2009, 47 (1), 295-298.

(49) Casanova, O.; Iborra, S.; Corma, A. Biomass into chemicals: aerobic oxidation of 5-hydroxymethyl-2-furfural into 2,5-furandicarboxylic acid with gold nanoparticle catalysts. ChemSusChem 2009, 2 (12), 1138-44.

(50) Davis, S. E.; Houk, L. R.; Tamargo, E. C.; Datye, A. K.; Davis, R. J. Oxidation of 5-hydroxymethylfurfural over supported Pt, Pd and Au catalysts. Catal. Today 2011, 160 (1), 55-60.

(51) Taitt, B. J.; Nam, D. H.; Choi, K. S. A Comparative Study of Nickel, Cobalt, and Iron Oxyhydroxide Anodes for the Electrochemical Oxidation of 5-Hydroxymethylfurfural to 2,5-Furandicarboxylic Acid. ACS Catal. 2019, 9 (1), 660-670.

(52) Jiang, N.; You, B.; Boonstra, R.; Terrero Rodriguez, I. M.; Sun, Y. Integrating Electrocatalytic 5-Hydroxymethylfurfural Oxidation and Hydrogen Production via Co-P-Derived Electrocatalysts. ACS Energy Lett. 2016, 1 (2), 386-390.

(53) Zhang, P.; Sheng, X.; Chen, X.; Fang, Z.; Jiang, J.; Wang, M.; Li, F.; Fan, L.; Ren, Y.; Zhang, B.; Timmer, B. J. J.; Ahlquist, M. S. G.; Sun, L. Paired Electrocatalytic Oxygenation and Hydrogenation of Organic Substrates with Water as the Oxygen and Hydrogen Source. Angew. Chem., Int. Ed. 2019, 58, 9155-9159.

(54) Nam, D. H.; Taitt, B. J.; Choi, K. S. Copper-Based Catalytic Anodes To Produce 2,5-Furandicarboxylic Acid, a Biomass-Derived Alternative to Terephthalic Acid. ACS Catal. 2018, 8 (2), 1197-1206.

(55) Yang, H. B.; Miao, J.; Hung, S. F.; Chen, J.; Tao, H. B.; Wang, X.; Zhang, L.; Chen, R.; Gao, J.; Chen, H. M.; Dai, L.; Liu, B. Identification of catalytic sites for oxygen reduction and oxygen evolution in N-doped graphene materials: Development of highly efficient metal-free bifunctional electrocatalyst. Sci. Adv. 2016, 2 (4), e1501122.

(56) Ci, L.; Song, L.; Jin, C.; Jariwala, D.; Wu, D.; Li, Y.; Srivastava, A.; Wang, Z. F.; Storr, K.; Balicas, L.; Liu, F.; Ajayan, P. M. Atomic layers of hybridized boron nitride and graphene domains. Nat. Mater. 2010, 9 (5), 430-5.

(57) Zhao, Y.; Yang, L.; Chen, S.; Wang, X.; Ma, Y.; Wu, Q.; Jiang, Y.; Qian, W.; Hu, Z. Can boron and nitrogen co-doping improve oxygen reduction reaction activity of carbon nanotubes? J. Am. Chem. Soc. 2013, 135 (4), 1201-4.

(58) Martin, D. J.; Qiu, K.; Shevlin, S. A.; Handoko, A. D.; Chen, X.; Guo, Z.; Tang, J. Highly efficient photocatalytic $\mathrm{H}_{2}$ evolution from water using visible light and structure-controlled graphitic carbon nitride. Angew. Chem., Int. Ed. 2014, 53 (35), 9240-5.

(59) Yang, L.; Jiang, S.; Zhao, Y.; Zhu, L.; Chen, S.; Wang, X.; Wu, Q.; Ma, J.; Ma, Y.; Hu, Z. Boron-doped carbon nanotubes as metalfree electrocatalysts for the oxygen reduction reaction. Angew. Chem., Int. Ed. 2011, 50 (31), 7132-5.

(60) Wang, S.; Zhang, L.; Xia, Z.; Roy, A.; Chang, D. W.; Baek, J. B.; Dai, L. BCN graphene as efficient metal-free electrocatalyst for the oxygen reduction reaction. Angew. Chem., Int. Ed. 2012, 51 (17), 4209-12.

(61) Tabbal, M.; Christidis, T.; Isber, S.; Mérel, P.; El Khakani, M. A.; Chaker, M.; Amassian, A.; Martinu, L. Correlation between the sp2-phase nanostructure and the physical properties of unhydrogenated carbon nitride. J. Appl. Phys. 2005, 98 (4), 044310.

(62) Zhang, J.; Zhang, G.; Chen, X.; Lin, S.; Mohlmann, L.; Dolega, G.; Lipner, G.; Antonietti, M.; Blechert, S.; Wang, X. Co-monomer control of carbon nitride semiconductors to optimize hydrogen evolution with visible light. Angew. Chem., Int. Ed. 2012, 51 (13), 3183-7.

(63) Barklie, R. C. Characterisation of defects in amorphous carbon by electron paramagnetic resonance. Diamond Relat. Mater. 2001, 10 (2), 174-181.
(64) Oshikiri, T.; Ueno, K.; Misawa, H. Selective Dinitrogen Conversion to Ammonia Using Water and Visible Light through Plasmon-induced Charge Separation. Angew. Chem., Int. Ed. 2016, 55 (12), 3942-6.

(65) Andersen, S. Z.; Colic, V.; Yang, S.; Schwalbe, J. A.; Nielander, A. C.; McEnaney, J. M.; Enemark-Rasmussen, K.; Baker, J. G.; Singh, A. R.; Rohr, B. A.; Statt, M. J.; Blair, S. J.; Mezzavilla, S.; Kibsgaard, J.; Vesborg, P. C. K.; Cargnello, M.; Bent, S. F.; Jaramillo, T. F.; Stephens, I. E. L.; Norskov, J. K.; Chorkendorff, I. A rigorous electrochemical ammonia synthesis protocol with quantitative isotope measurements. Nature 2019, 570 (7762), 504-508.

(66) Vuyyuru, K. R.; Strasser, P. Oxidation of biomass derived 5hydroxymethylfurfural using heterogeneous and electrochemical catalysis. Catal. Today 2012, 195 (1), 144-154.

(67) Chadderdon, D. J.; Xin, L.; Qi, J.; Qiu, Y.; Krishna, P.; More, K. L.; Li, W. Z. Electrocatalytic oxidation of 5-hydroxymethylfurfural to 2,5-furandicarboxylic acid on supported $\mathrm{Au}$ and $\mathrm{Pd}$ bimetallic nanoparticles. Green Chem. 2014, 16 (8), 3778-3786.

(68) Dijkman, W. P.; Groothuis, D. E.; Fraaije, M. W. Enzymecatalyzed oxidation of 5-hydroxymethylfurfural to furan-2,5-dicarboxylic acid. Angew. Chem., Int. Ed. 2014, 53 (25), 6515-8. 